\title{
Qualidade pós-colheita de frutos de mangueira (Mangifera indica L) var. 'Tommy Atkins' sob sistema orgânico no submédio São Francisco (Brasil)
}

Recibido: 2 Febreiro 2007 / Aceptado: 10 Outubro 2008

(C) IBADER- Universidade de Santiago de Compostela 2008

Resumo O objetivo do trabalho foi avaliar a qualidade pós colheita de frutos de mangueira Tommy Atkins, cultivada sob sistema orgânico. Os frutos foram avaliados logo ao chegarem ao laboratório (0) e após armazenamento em câmara fria a $10,5^{\circ} \pm 1^{\circ} \mathrm{C}$ e $85,5^{\circ} \pm 5 \%$ de UR, durante, 14 , 28 e 42 dias após a colheita (DAC), sendo que após cada período, foram retirados da câmara fria e mantidos durante quatro dias a $21 \pm 1^{\circ} \mathrm{C}$ e $55-65 \%$ de UR, após o que foram caracterizados física, biológica e químicamente. $\mathrm{O}$ delineamento experimental foi em blocos inteiramente ao acaso. As médias foram comparadas pelo teste de Tukey. Os frutos foram avaliados quanto a: perda de água e a aparência, danos mecânicos, coloração da casca, firmeza da polpa, ocorrência de colapso interno, escurecimento de lenticelas, danos por lesões devido ao ataque de Lasiodiplodia, Colletotrichum ou por Alternaria ou por tripes; SST, ATT e o pH da polpa. As mangas estavam aptas para o consumo por volta dos 18 DAC, tempo, mais do que suficiente para se proceder ao transporte do produto até mercados distantes, como o americano e o europeu.

P.A. da C. Pinto

Professor Pleno da UNEB/DTCS, 48905680 Juazeiro - BA. Fone: (74) 36117363.

e-mail: pacostapinto@gmail.com; Home page:

http://br.geocities.com/pacostapinto

C.M.M. Choudhury

Pesquisador da EMBRAPA/CPATSA, Ph.D., Petrolina - PE

J.A. de Lins - Consultor em Agricultura Orgânica

S. Homma

M.Sc., Coordenador Técnico da Fundação Mokiti Okada, SP

A.C.C Pinto

Professor do SENAC, Petrolina, PE.

C.P da Silva - Técnico Agrícola

R.S. Oliveira - Estudante de Engenharia Agronômica na UNEB/DTCS
Termos de indexação agricultura sustentável · atributos físicos, biológicos e químicos · agro-ecossistemas

Summary The aim of the study was to assess the quality of post-harvest fruit of mango Tommy Atkins, under organic system cultivation. The fruits had been evaluated shortly when arriving at the laboratory $(0)$ and after storage in cold chamber $10,5^{\circ} \pm 1^{\circ} \mathrm{C}$ and $85,5^{\circ} \pm 5 \%$ of UR, during, 14,28 and 42 days after the harvest (DAH), being that after each period, had been removed of the cold chamber and kept during four days the $21 \pm 1^{\circ} \mathrm{C}$ and $55-65 \%$ of UR, after what they had been evaluated physical, biological and chemically. The experimental design was in blocks entirely at random. The averages were compared by test Tukey $(p<0,05)$. The fruits had been evaluated how much: loss of water and the appearance, mechanical damages, coloration of the bark, firmness of the pulp, occurrence of internal collapse, blackout of lenticels, damages due to injuries from attack of Lasiodiplodia, Colletotrichum or Alternate or for Tripods; SST, ATT and $\mathrm{pH}$ of the pulp. The mango were apt for the consumption for return of the $18 \mathrm{DAH}$, time, what more than enough to proceed the transport of the product until distant markets, as the American and the European.

Key words Sustainable agriculture · physical, biological and chemical attributes $\cdot$ agro-ecosystems

\section{Introdução}

Em 2003, a dimensão da agricultura orgânica brasileira de acordo com a Federação Internacional de Movimentos de Agricultura Orgânica (IFOAM), era de 841 mil hectares em 19.000 propriedades (Camargo et al., 2006).

Atualmente o Brasil possui a segunda maior área de produção agrícola orgânica no mundo, perdendo apenas para a Austrália.

A comercialização de produtos orgânicos brasileiros cresce anualmente 0 dobro da média mundial, em uma porcentagem estimada em 50,0 \%. Além disso, o Brasil 
possui 87,0 \% das novas áreas agricultáveis de orgânicos do mundo e conta com a maior reserva de recursos naturais (Camargo et al., 2006).

Conforme a Comissão do Codex Alimentarius da Organização Mundial da Saúde, OMS/FAO, cultivo orgânico é um sistema de manejo da produção holístico, que promove e valoriza agro-ecossistemas saudáveis, incluindo biodiversidade, ciclos biológicos e atividade biológica dos solos (lyer, 2004).

Assim, os principais objetivos do cultivo orgânico são: a) produzir alimentos em quantidade e de alta qualidade nutricional; b) interagir em um construtivo modo de valorização da vida em ciclos e sistemas naturais; c) encorajar e valorizar ciclos biológicos dentro de um sistema de cultivo envolvendo microrganismos, flora e fauna do solo, plantas e animais; dentre outros (Nampoothiri, 2001).

Bem diferente do que se faz na mangicultura convencional, no sistema orgânico não se usa nenhum produto químico sintético, seja fertilizante ou defensivo agrícola, minimizando riscos ao ambiente e consumidores (Ciociola Junior \& Martinez, 2002).

Brito (2004) fez uma comparação econômico - financeira da viabilidade da produção da manga orgânica, comparando-a com a da manga convencional no Pólo de Desenvolvimento Integrado de Juazeiro - Petrolina, mediante pesquisa com os produtores que já possuem Projetos Certificados, os em processo de conversão e os produtores convencionais. A análise demonstrou que a produção orgânica, mesmo possuindo uma produtividade inferior ao longo de sua vida útil, e custos iniciais nos três primeiros anos de produção superiores à produção convencional, ao longo do período analisado, se torna mais vantajosa, retornando para o empreendimento valores mais expressivos e mais rapidamente. "O retorno do investimento na produção orgânica é mais rápido do que o retorno da agricultura convencional, sendo superior em 05 (cinco) meses, valores esses comprovados através do cálculo do PAYBACK; no longo prazo, a produção orgânica retorna para a empresa rural um valor maior do que a produção convencional, conforme podemos comprovar com o uso do índice de Valor Presente Líquido - VPL, que retornou para a empresa um valor de $\mathrm{R} \$ 46.998,11$ superior em $\mathrm{R} \$ 22.151,41$ o valor apresentado pelo sistema de produção convencional, que foi no montante de $\mathrm{R} \$ 24.846,70$. Os rendimentos previstos no futuro, valem no presente, considerada uma taxa de remuneração de $10 \%$ ao ano, um valor a mais para a agricultura orgânica em R\$22.151,41" (Brito, 2004).

Barbosa et al. (2005) realizaram prospecções em duas áreas comerciais de mangueira, var. Tommy Atkins, conduzidas em dois sistemas de manejo: produção integrada e orgânica no Vale do São Francisco não observando diferença na constância das pragas e predadores nos dois sistemas de cultivo estudados, com exceção dos ácaros Oligonychus sp. e Rubroscirus sp., constatando-se menor ocorrência no sistema orgânico.

Neto (2005) testando o uso de farinha de rocha em pomares de manga Tommy Atkins no Vale do São Francisco irrigados por micro aspersão, verificou que nos pomares de manga houve uma melhora geral do aspecto visual e vigor das plantas, e aumentos significativos da produtividade e uma redução muito significativa na incidência de doenças, permitindo a diminuição do número de aplicações de fungicidas.

O objetivo do presente trabalho foi caracterizar a qualidade pós - colheita de frutos de mangueira Tommy Atkins, cultivada sob sistema orgânico no submédio do Vale do Rio São Francisco.

\section{Material e métodos}

O experimento foi desenvolvido com mangas Tommy Atkins, colhidas no dia 07.11.06 em pomar comercial do Projeto de Irrigação Roça Dunas, município de Curaçá - BA (Latitude S $8^{\circ} 56^{\prime} 36$ ", Longitude W 39 52' 38", Altitude $365 \mathrm{~m}$ ), conduzido sob o sistema orgânico, localizado no Pólo Agrícola Juazeiro, BA - Petrolina, PE. O clima da região é quente, seco e semi-árido, com precipitação anual média de $400 \mathrm{~mm}$, e temperatura máxima média de $28^{\circ} \mathrm{C}$ e mínima média de $24,6^{\circ} \mathrm{C}$. O solo é um NEOSSOLO FLÚVICO eutrófico, A moderado, muito profundo, textura média, fase caatinga hiperxerófila, relevo suave ondulado. O pomar é formado com árvores de pouco mais de 10 anos de idade, espaçamento $8 \times 8 \mathrm{~m}$. A análise de solo, 0 a $20 \mathrm{~cm}$, feita em 02.06.06 revelou: $\mathrm{pH} \mathrm{H}_{2} \mathrm{O}=6,5 ; \mathrm{Ca}^{++}=1,6 \mathrm{cmol}_{\mathrm{c}} \mathrm{dm}^{-3} ; \mathrm{Mg}^{++}=$ $1,7 \mathrm{cmol}_{\mathrm{c}} \mathrm{dm}^{-3} ; \mathrm{K}^{+}=0,3 \mathrm{cmol}_{\mathrm{c}} \mathrm{dm}^{-3} ; \mathrm{Na}^{+}=0,0 \mathrm{cmol}_{\mathrm{c}} \mathrm{dm}^{-3} ; \mathrm{Al}^{+++}=$ $0,0 \mathrm{cmol}_{\mathrm{c}} \mathrm{dm}^{-3} ; \mathrm{H}+\mathrm{Al}=1,2 \mathrm{cmol}_{\mathrm{c}} \mathrm{dm}_{-3 ;} \mathrm{P}$ disp. (Mehlich I) $=$ $19 \mathrm{mg} \mathrm{dm}-3 ; \mathrm{C}$ org. $=6,3 \mathrm{~g} \mathrm{~kg}^{-1} ; \mathrm{MOS}=10,86 \mathrm{~g} \mathrm{~kg}^{-1} ; \mathrm{SB}=3,6$ cmolc dm-3; $\mathrm{T}=4,8$ cmolc $\mathrm{dm}-3 ; \mathrm{V}=75 \%$; CEes $=0,5 \mathrm{dS}$ $\mathrm{m}-1 ;$ areia $=48 \% ;$ silte $=44 \% ;$ argila $=8 \% ; \mathrm{d}_{\text {solo }}=1,49 ;$ $\mathrm{d}_{\text {particula }}=2,61 \mathrm{~g} \mathrm{~cm}^{-3}$; água retida a $0,33 \mathrm{~atm}=15,09 \%$ e a 15 $\mathrm{atm}=6,49 \%$. A análise de Folhas feita em 27.01.06 revelou: $\mathrm{N}=8,83 ; \mathrm{P}=2,10 ; \mathrm{K}=10,50 ; \mathrm{Ca}=43,56 ; \mathrm{Mg}=$ 1,$55 ; \mathrm{S}=1,03 \mathrm{~g} \mathrm{~kg}-1 ; \mathrm{B}=58,33 ; \mathrm{Cu}=10,00 ; \mathrm{Fe}=42,10 ; \mathrm{Mn}$ = 296,00; $\mathrm{Zn}=41,20 ; \mathrm{Na}=290 \mathrm{mg} \mathrm{kg}^{-1}$.

A área desde o ano de 1999 vem sendo conduzida sob manejo orgânico de agricultura natural. No Quadro 1 são indicados os insumos utilizados e detalhes do sistema de produção.

Após a colheita de frutos em 2005 foram feitas podas de limpeza dos ramos secos ou doentes com Fusarium ou com Botryodiploidia, favorecendo as brotações, melhorando a exposição dos ramos ao sol e coloração dos frutos, mantendo as árvores mais baixas, favorecendo os tratos culturais e qualidade dos frutos, usando três podas: a) de levantamento de copa com eliminação dos ramos que estiverem abaixo de $0,70 \mathrm{~m}$ de altura; $\mathrm{b}$ ) de abertura central da copa, eliminando-se ramos com ângulo de inserção com o tronco menor que $45^{\circ}$; c) lateral para manter o espaçamento entre fileiras e facilitar o manejo da cultura. Os ramos grossos foram pincelados com pasta bordalesa, para evitar a penetração de patógenos. Foi feita irrigação por microaspersão, variando o tempo de irrigação com o estádio de desenvolvimento do fruto. As árvores sofreram indução do florescimento por estresse hídrico por 56 dias e no período de quebra da dormência, o intervalo de irrigações foi de 2 a 3 dias. Foram feitas pulverizações manuais com calda à base de urina de vaca a $6 \%$ e Garden 


\begin{tabular}{|c|c|c|c|c|c|c|c|}
\hline \multirow[t]{2}{*}{ Ano } & \multicolumn{7}{|c|}{ QUANTIDADES APLICADAS POR PLANTA } \\
\hline & $\begin{array}{l}\text { MB4 ou } \\
\text { similar }\end{array}$ & $\begin{array}{l}\text { Fosfato } \\
\text { natural }\end{array}$ & $\begin{array}{l}\text { Composto } \\
\text { laminar }\end{array}$ & $\begin{array}{l}\text { EM4 } \\
\text { Melaço }\end{array}$ & $\begin{array}{l}\text { EM5 ou } \\
\text { similar }\end{array}$ & $\begin{array}{l}\text { Indução } \\
\text { floral }\end{array}$ & $\begin{array}{l}\text { Outros tratamentos } \\
\text { especificos }\end{array}$ \\
\hline 1999 & $4 \mathrm{~kg}$ & $\begin{array}{l}\text { Gafsa } \\
2,0 \mathrm{~kg}\end{array}$ & $\begin{array}{l}\text { Esterco } \\
\text { animal } 1 \\
\text { parte } \\
\text { Bagaço de } \\
\text { cana 3 } \\
\text { partes }\end{array}$ & $\begin{array}{l}\text { EM4 - 1L + } \\
\text { Melaço 1L / } \\
100 \text { L Água } \\
\text { sobre o } \\
\text { composto }\end{array}$ & $2 \%$ foliar & $\begin{array}{l}\text { EM4+EM5+ } \\
\text { urina de vaca a } \\
5 \%\end{array}$ & $\begin{array}{l}\text { Irrigação por gravidade } \\
\text { linundação }\end{array}$ \\
\hline 2000 & $4 \mathrm{~kg}$ & $\begin{array}{l}\text { Gafsa } \\
1,5 \mathrm{~kg}\end{array}$ & Mato & $\begin{array}{l}\text { EM } 4-1 \mathrm{~L}+ \\
\text { Melaço - } \\
1 \mathrm{~L} / 100 \mathrm{~L} \\
\text { Água sobre } \\
\text { o composto }\end{array}$ & $2 \%$ foliar & $\begin{array}{l}\text { EM4+EM5 + } \\
\text { urina de vaca a } \\
5 \%\end{array}$ & $\begin{array}{l}\text { Irrigação por gravidade } \\
\text { linundação }\end{array}$ \\
\hline 2001 & $\begin{array}{l}3 \mathrm{~kg}+ \\
\text { Fosfato } \\
\text { Natural } \\
\text { de Irecê } \\
2,0 \mathrm{~kg}\end{array}$ & $\begin{array}{l}\text { Terra } \\
\text { de Ipirá } \\
5 \text { kg }\end{array}$ & $\begin{array}{l}\text { Mato } \\
\text { Cinza de } \\
\text { madeira } \\
\text { 3Kg/ planta }\end{array}$ & $\begin{array}{l}\text { Nutri } \\
\text { Bokashi } \\
1 \mathrm{~kg} \text { (solo) }\end{array}$ & $\begin{array}{l}\text { Biocontrol } \\
\text { (para trips) } \\
\text { foliar }\end{array}$ & $\begin{array}{l}\text { EM4 a } 2 \%+ \\
\text { urina de vaca a } \\
3 \%\end{array}$ & $\begin{array}{l}\text { Cinza de madeira como } \\
\text { fonte de } \mathrm{K}\end{array}$ \\
\hline 2002 & $2 \mathrm{~kg}$ & $\begin{array}{l}\text { F.N. de } \\
\text { lrecê } 1 \\
\mathrm{~kg}\end{array}$ & $\begin{array}{l}\text { Cinza de } \\
\text { madeira } 3 \\
\mathrm{~kg}+ \\
\text { Mato }\end{array}$ & $\begin{array}{l}\text { Em4 - 1 L } \\
+ \text { Melaço 1 } \\
\text { L/ } 100 \text { L } \\
\text { Água + } \\
\text { Nutri } \\
\text { Bokashi } \\
3 \text { kg (solo) }\end{array}$ & & $\begin{array}{l}\text { Garden } \\
\text { Bokashi" + } \\
\text { urina de vaca a } \\
5 \%\end{array}$ & \\
\hline 2003 & $4 \mathrm{~kg}$ & $2 \mathrm{~kg}$ & $\begin{array}{l}\text { Cinza de } \\
\text { madeira } 5 \\
\text { kg/planta }\end{array}$ & $\begin{array}{l}\text { Nutri } \\
\text { Bokashi } 4 \mathrm{~kg}\end{array}$ & $\begin{array}{l}\text { Garden } \\
\text { Bokashi } \\
4: 100 \\
\text { Solo }\end{array}$ & $\begin{array}{l}\text { Garden Bokashi } \\
+ \\
\text { urina de vaca? }\end{array}$ & \\
\hline 2004 & $\begin{array}{l}\text { Natural } \\
\text { Plus }{ }^{\star \star \star \star} \\
10 \mathrm{~kg}\end{array}$ & & $\begin{array}{l}\text { Cinza de } \\
\text { madeira } 2 \\
\mathrm{~kg}\end{array}$ & $\begin{array}{l}\text { Nutri } \\
\text { Bokashi } 4 \text { kg }\end{array}$ & $\begin{array}{l}\text { Garden } \\
\text { Bokashi } \\
4 \mathrm{~L} / 100 \mathrm{~L} \\
\text { água } \\
\text { (Solo) }\end{array}$ & $\begin{array}{l}\text { Urina de vaca } 5 \\
\%+\text { cloreto de } \\
\text { sódio } 1 \% \\
\text { (animal, sal de } \\
\text { pedra) }\end{array}$ & $\begin{array}{l}\text { Ulexita natural }{ }^{\cdots} 200 \mathrm{~g} \\
\text { na época de chuva e na } \\
\text { floração + Zn SO }{ }_{4} 60 \mathrm{~g} \\
+ \text { Sul-Po-Mag } 300 \mathrm{~g} \mathrm{(2} \\
\text { X) }\end{array}$ \\
\hline 2005 & $\begin{array}{l}\text { Natural } \\
\text { Plus } \\
10 \mathrm{~kg}\end{array}$ & & $\begin{array}{l}\text { Manejo do } \\
\text { mato } \\
\text { espontâneo }\end{array}$ & $\begin{array}{l}\text { Nutri } \\
\text { Bokashi } \\
3 \text { kg (solo) }\end{array}$ & $\begin{array}{l}\text { Garden } \\
\text { Bokashi } \\
4 \mathrm{~L} / 100 \mathrm{~L} \\
\text { água } \\
\text { (Solo) }\end{array}$ & $\begin{array}{l}\text { Estresse hídrico } \\
+ \text { fumaça da } \\
\text { queima da fibra } \\
\text { de coco }\end{array}$ & $\begin{array}{l}\text { Ulexita natural }{ }^{\cdots} 200 \mathrm{~g} \\
\text { na época de chuva e na } \\
\text { floração }+\mathrm{Zn} \mathrm{SO}{ }_{4} 60 \mathrm{~g} \\
\text { pegamento frutos }+\mathrm{Sul} \text { - } \\
\text { Po-Mag } 300 \mathrm{~g}(2 \mathrm{X}) \\
\text { (tudo solo) }\end{array}$ \\
\hline 2006 & $\begin{array}{l}\text { Natural } \\
\text { Plus } \\
10 \mathrm{~kg}\end{array}$ & & $\begin{array}{l}\text { Cinza de } \\
\text { madeira? }\end{array}$ & $\begin{array}{l}\text { Nutri } \\
\text { Bokashi } \\
4 \text { kg (solo) } \\
\text { Garden } \\
\text { Bokashi } 2 \\
\text { L/100 L } \\
\text { água }\end{array}$ & $\begin{array}{l}\text { Ferti } \\
\text { Bokashi } \\
2 \mathrm{~L} / 100 \mathrm{~L} \\
\text { água } \\
\text { Solo }\end{array}$ & $\begin{array}{l}\text { Estresse hidrico } \\
+ \text { fumaça da } \\
\text { queima da fibra } \\
\text { de coco }\end{array}$ & $\begin{array}{l}\text { Ulexita }+\ldots+\ldots \text { idem } \\
2005 .\end{array}$ \\
\hline
\end{tabular}

Fertilizante orgânico composto, de natureza farelada, fermentado e de baixa umidade com farelo de arroz, torta de mamona, casca de arroz moída e farinhas de pena.

Produto semelhante ao Nutri Bokashi.

Borato de sódio e cálcio $5 \mathrm{~B}_{2} \mathrm{O}_{3} .2 \mathrm{CaO} . \mathrm{Na}_{2} \mathrm{O} .16 \mathrm{H}_{2} \mathrm{O}$.

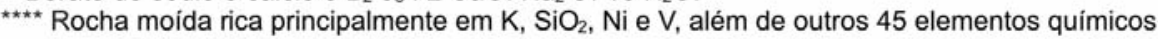

Quadro 1.- Insumos utilizados e outros tratamentos específicos utilizados no sistema orgânicos de produção de manga 'Tommy Atkins'

Bokashi. Quando a floração alcançou $30 \%$ dos ramos, o intervalo entre irrigações foi de 3 a 4 dias. Na fase de desenvolvimento e maturação dos frutos a cada 6 a 8 dias. Aproximadamente 60 a 70 dias após a floração foi feita a limpeza de panículas, eliminando-se partes secas, frutos amarelados e mal formados. Foram eliminadas as folhas que tocavam ou cobriam os frutos, objetivando melhor cor dos frutos. Para evitar queimaduras dos frutos pelos raios solares aqueles voltados para o oeste foram pincelados com calda de cal super refinada (3 $\mathrm{kg}$ para $15 \mathrm{~L}$ de água, mais espalhante adesivo), após a limpeza das panículas e 20 a 30 dias antes da colheita.

Os frutos foram colhidos no ponto de maturação quando a polpa apresenta pigmentação amarela em até $25 \%$ (Nota 2) conforme empregado na região para exportação (EUA e Europa) (Galán Saúco, 1999). 
No laboratório de Pós-Colheita do Centro de Pesquisas Agropecuárias do Trópico Semi-Árido (CPATSA/EMBRAPA) foram feitas as avaliações do trabalho. Neste local os frutos foram lavados com água corrente, secos com flanela, e cerca de 100 frutos foram classificados e acondicionados em caixas de papelão ondulado telescópico, com dimensões de $41 \times 24 \times 11 \mathrm{~cm}$ e a tampa com $44 \times 28 \times$ $11 \mathrm{~cm}$, com capacidade para 11 frutos. Os tratamentos de armazenamento foram: $0 ; 14+4 ; 28+4 ; 42+4$ (dias). Os frutos foram avaliados logo ao chegarem ao laboratório (0) e após armazenamento em câmara fria $\left(10,5^{\circ} \pm 1^{\circ} \mathrm{C}\right.$ e 85,5 $\pm 5 \%$ de UR) durante o período de 14,28 e 42 dias após a colheita (DAC), sendo que após cada período, foram retirados da câmara fria e mantidos durante quatro dias em sala de amadurecimento $\left(21 \pm 1^{\circ} \mathrm{C}\right.$ e $55-65 \%$ de UR), após o que foi feita a avaliação dos atributos físicos, biológicos e químicos. Físicos: 1) Peso médio de fruto; 2) Perda de massa, por meio de método gravimétrico. 3) Aparência dos frutos (quando os defeitos na casca - arranhões, manchas, danos causados por insetos) assumindo notas: 0 , totalmente perfeita; 1 , não totalmente perfeita, $\geq 0,1 \%$ e $\leq$ $3,0 \%$; 2 , levemente defeituosa, $\geq 3,1 \%$ e ? $10,0 \% ; 3$, moderadamente defeituosa, ? $10,1 \%$ e $\leq 25,0 \% ; 4$, defeituosa, $\geq 25,1 \%$ e $\leq 30,0 \% ; 5$, totalmente defeituosa, $\geq$ $30,1 \%$, não aceitável comercialmente, conforme critério adotado pelo Laboratório de Pós-Colheita do CPATSA/EMBRAPA; 4) Danos mecânicos, conforme notas: $0,0 \%$; 1,1 a $5 \%$; 2, 5,1 a $10 \%$; 3, 10,1 a $25 \%$; 4, 25,1 a $50 \%$; , > 50,1 \%.; 5) Coloração da casca, avaliada conforme critério adotado pelo Laboratório de Pós-Colheita do CPATSA/EMBRAPA. Coloração de fundo: se totalmente verde, nota 0 ; se quase totalmente verde, nota 1; se o verde é > amarelo, nota 2; se amarelo = verde, nota 3; se amarelo $>$ verde, nota 4; se totalmente amarelo, nota 5 ; coloração roxa (\%): 0 , nota 0 ; até 10 , nota $1 ; 10,1$ a 25 , nota $2 ; 25,1$ a 50 , nota $3 ; 50,1$ a 75 , nota $4 ; 75,1$ a 100 , nota 5 .

6) Coloração da polpa, sem iodo; notas: 0, Branco (100\%); 1 , branco com nuances amarelo-claro até $50 \% ; 2$, predominância do amarelo-claro (50,1\% a $90 \%)$; 3, amarelo $(90,1 \%$ a $100 \%) ; 4$, amarelo intenso $(100 \%)$ com nuances alaranjadas; 5 , amarelo alaranjado (> 50\%). Coloração da polpa, com iodo; notas: 0 , polpa escura, totalmente tingida; 1 , clareamento inferior a $10 \% ; 2$, clareamento entre $10,1 \%$ e $30 \%$; 3, clareamento entre $30,1 \%$ e $50 \%$; 4, clareamento acima de $50,1 \% ; 5$, ausência de escurecimento da polpa; 7 ) Firmeza da polpa, removendo-se a parte da casca em ambos os lados da fruta e em seguido fazendo-se duas leituras, uma no ombro dorsal e outra no ombro ventral, utilizando penetrômetro com diâmetro de ponteira igual a $0,8 \mathrm{~cm}, 2,6 \mathrm{~cm}$ de altura o qual expressa o valor em $\mathrm{Kgf} \mathrm{cm}$ 2; Biológicos: 8) Incidência do Colapso Interno: foi avaliada em cada fruto, cortando-os longitudinalmente, de maneira a expor os tecidos para a avaliação do distúrbio. Os sintomas foram verificados visualmente. Os resultados foram expressos em percentagem em relação ao número total de frutos analisados, atribuindo-se notas (\%): $0,0 \% ; 1,1$ a 5 $\%$; 2, 5,1 a $10 \%$; 3, 10,1 a $25 \%$; 4, 25,1 a $50 \% ; 5,>50,1$ \%; 9) Deteriorações por Ocorrência de Lasiodiplodia, Colletotrichum e Alternaria, atribuindo-se notas ( 0 , quando a área lesionada não existe; 1 , se de 0,1 a $5 \% ; 2$, se de 5,1 a $10 \%$; 3 , se de 10,1 a $25 \%$; 4 , se de 25,1 a $50 \%$; 5 , se >
$50,1 \%)$ conforme critério adotado pelo Laboratório de PósColheita do CPATSA/EMBRAPA; 10) Frutos apodrecidos; 11) Danos causados por Tripes e Lenticelas, conforme notas e área lesionada (\%); 0, $0 \% ; 1,0,1$ a $5 \% ; 2,5,1$ a 10 \%; 3, 10,1 a $25 \%$; 4, 25,1 a $50 \%$; 5, >50,1\%; Químicos: Conforme o Instituto Adolfo Lutz (1985) foram feitos 12) Sólidos Solúveis Totais (SST) determinados mediante o uso de refratômetro; 13) Acidez Total Titulável (ATT) determinada utilizando-se $10 \mathrm{~mL}$ de suco dos frutos triturada em liquidificador e transferida para erlenmeyer de $250 \mathrm{~mL}$, ao qual foram acrescentados $100 \mathrm{~mL}$ de água destilada e 3 gotas de solução de fenolftaleína $0,1 \mathrm{~g} / 100 \mathrm{~mL}$ de etanol, em seguida titulando-se com $\mathrm{NaOH} \mathrm{0,1} \mathrm{mol} / \mathrm{L}$, havendo viragem do hialino para a cor rosa. A leitura é multiplicada por um fator 0,064023. A acidez foi expressa em miligramas de ácido cítrico por $100 \mathrm{~mL}$ de suco, conforme o Instituto Adolfo Lutz (1985); 14) pH da polpa, mediante uso de pHmetro, após trituração da polpa com água destilada em liquidificador, empregando-se $25 \mathrm{~mL}$ de suco concentrado (Instituto Adolfo Lutz, 1985); 15) Relação entre sólidos solúveis totais/acidez total titulável (SST/ATT); O delineamento experimental utilizado foi em blocos inteiramente casualizados. As médias foram comparadas pelo teste de Tukey $(p<0,05)$.

\section{Resultados e discussão}

No Quadro 2 são apresentados os resultados médios das avaliações de atributos físicos de frutos de mangueira Tommy Atkins cultivada sob sistema orgânico.

Não se constatou diferença significativa entre os pesos médios de frutos nos diferentes períodos de avaliação (Quadro 2).

A perda de água pelos frutos sob armazenamento em câmara fria aumentou com o tempo, não sendo significativa até 14 dias a $10,5 \pm 1^{\circ} \mathrm{C}$ e $85,5 \pm 5 \%$ de UR e mais 4 dias à $21 \pm 1^{\circ} \mathrm{C}$ e $55-65 \%$ de UR, senão após 32 e 46 dias após colheita (DAC), o equivalente a 9,99 e $7,72 \%$ respectivamente (Quadro 2).

Avaliando mangas Tommy Atkins produzidas em dez pomares de alta produtividade sob sistema convencional, Pinto (2002) verificou que as perdas de água pelos frutos armazenados à $21 \pm 1^{\circ} \mathrm{C}$ e $55-65 \%$ de UR aumentaram, em média, de 2,64 a 9,15\%, entre 10 e 40 dias de armazenamento, respectivamente. Quando os frutos foram armazenados em câmara de refrigeração $\left(10 \pm 1^{\circ} \mathrm{C}\right.$ e UR 90 a $95 \%$ ) as perdas de água foram menores, variando, em média, de 1,80 a $6,38 \%$ aos 10 e aos 40 DAC, respectivamente.

O teor de água de frutos da mangueira é da ordem de $80 \%$ e a perda de massa durante o transporte e o armazenamento pode ser considerável. Uma perda de massa de 5 a $10 \%$ em frutos e hortaliças promove um visível enrugamento (Vilas Boas, 1999). 


\begin{tabular}{|c|c|c|c|c|c|c|c|c|c|}
\hline \multirow{2}{*}{$\begin{array}{l}\text { Tratamentos } \\
\text { (Dias) }\end{array}$} & \multirow{2}{*}{$\begin{array}{l}\text { Peso } \\
\text { Médio } \\
\text { (g) }\end{array}$} & \multirow{2}{*}{$\begin{array}{c}\begin{array}{c}\text { Perda } \\
\text { de }\end{array} \\
\text { Peso } \\
(\%)\end{array}$} & \multirow{2}{*}{ Aparência } & \multirow{2}{*}{$\begin{array}{c}\text { Danos } \\
\text { Mecânico }\end{array}$} & \multicolumn{2}{|c|}{ Coloração } & \multicolumn{2}{|c|}{ Coloração } & \multirow{2}{*}{$\begin{array}{c}\text { Firmeza } \\
\left(\mathrm{kgf} \mathrm{cm}^{-2}\right)\end{array}$} \\
\hline & & & & & Casca ${ }^{1}$ & Casca $^{2}$ & $\mathrm{Polpa}^{3}$ & Polpa $^{4}$ & \\
\hline 0 & $422,01 a^{y}$ & $0,00 \mathrm{~b}$ & $2,00 a$ & $0,13 b$ & $2,77 \mathrm{c}$ & $3,37 b$ & $2,70 c$ & $0,00 c$ & $11,57 a$ \\
\hline $14+4^{x}$ & $430,60 a$ & $1,91 \mathrm{~b}$ & $2,60 a$ & $0,55 a b$ & $4,20 \mathrm{~b}$ & $3,80 \mathrm{ab}$ & $3,05 c$ & $2,60 \mathrm{~b}$ & $4,17 \mathrm{~b}$ \\
\hline $28+4$ & $440,48 a$ & $9,99 a$ & $2,20 a$ & $0,50 a b$ & $4,80 a b$ & $4,50 a$ & $4,85 a$ & $4,90 a$ & $0,00 c$ \\
\hline $42+4$ & $423,55 a$ & $7,72 a$ & $2,60 a$ & $1,10 a$ & $4,95 a$ & 4,20ab & $4,00 \mathrm{~b}$ & $4,90 a$ & $0,02 c$ \\
\hline CV (\%) & 5,50 & 42,17 & 17,48 & 80,43 & 1,91 & 11,40 & 10,50 & 7,68 & 37,11 \\
\hline
\end{tabular}

${ }^{\times}$Quatro dias sob a temperatura d e $21 \pm 1^{\circ} \mathrm{C}$ e $55-65 \%$ de UR ao final do período de 14,28 ou 42 dias de armazenamento sob refrigeração de $10,5 \pm 1^{\circ} \mathrm{C}$ e $85 \pm 5 \%$ de UR;

${ }^{y}$ Médias seguidas de mesma letra na coluna não diferem entre si pelo teste de Tukey ao nivel de $5 \%$ de probabilidade.

${ }^{1}=$ Coloração verde $;^{2}=$ Coloração Roxa; ${ }^{3}=$ Coloração sem lodo $e^{4}=$ Coloração com lodo

Quadro 2.- Valores médios das avaliações de atributos físicos de frutos de mangueira cv. Tommy Atkins, provenientes de cultivo orgânico, Curaçá - BA, 2006-2007, imediatamente após a colheita e após conservação sob refrigeração

Considerando que no presente trabalho os frutos produzidos sob sistema orgânico ficaram parte do tempo sob refrigeração e também em sala de amadurecimento à temperaturas mais altas, os valores de perda de massa dos frutos não foram tão superiores àqueles verificados por Pinto (2002), com frutos de pomares convencionais.

Quanto à aparência dos frutos, não se constatou diferenças significativas nos diferentes tempos de avaliação (Quadro 2).

Os danos mecânicos nos frutos mostraram-se significativamente maiores aos 46 DAC, em relação ao tempo da colheita (Quadro 2).

A coloração da casca dos frutos intensificou-se à medida que aumentou o tempo de armazenamento, até aos 32 DAC (Quadro 2). Durante o amadurecimento da manga Tommy Atkins, a clorofila é rapidamente degradada, enquanto antocianinas se acumulam (Medlicott et al., 1986, citados por Gomez - Lim, 1997). Ao mesmo tempo, um aumento nos carotenóides totais pode ser detectado. A síntese de carotenóides em mangas envolve como precursores o ácido mevalonico (precursor do isopentenil pirofosfato II, unidade construtora básica de terpenóides) e o geraniol $(\mathrm{C} 10 \mathrm{H} 18 \mathrm{O})$ (Mattoo et al., 1968, citados por Gomez - Lim, 1997), isto é, a rota isoprenoide. Esses dois compostos se acumulam antes da elevação climatérica, mas diminuem a concentração durante o período climatérico. Assim um concomitante incremento na atividade da fosfatase foi observado por Mattoo et al.(1968), citados por Gomez - Lim (1997), concluindo que a atividade da fosfatase foi um importante fator regulador da produção de caroteno na manga. Este último processo parece ocorrer na casca e na polpa, acompanhado por mudanças na ultra-estrutura de plastídios (Parikh \& Modi, 1990, citados por Gomez - Lim, 1997).

De acordo com Lee et al., 1987, citados por Schaffer et al. (1994), a cor da casca em frutos é devida a antocianinas que se desenvolvem quando os tecidos são expostos à luz. O papel das antocianinas não é plenamente entendido, embora se tenha sugerido que a mesma se desenvolve como quando um filme é exposto à radiação ultravioleta, ou como o produto do metabolismo de outros compostos flavonóides que são sintetizados no tecido.

A firmeza da polpa assumiu valores médios da ordem de $11,57 \mathrm{kgf} \mathrm{cm}^{-2}$, sendo reduzida significativamente aos 18 DAC, assumindo valor 4,17 , caindo a zero aos 32 DAC (Quadro 2). No México tem-se considerado adequada a colheita da manga Tommy Atkins em cultivos convencionais, com firmeza de 12,4 kgf cm-2 (Báez \& Bringas, 1996 citados por Saúco, 1999). Em dez pomares convencionais (Pinto, 2002) a média de firmeza da polpa dos frutos foi 9,$99 ; 4,15$; 1,41 e 1,65 kgf cm-2, imediatamente após a colheita aos 10, 30 e 40 DAC, respectivamente. Entre os tempos houve diferença estatística entre os tratamentos para a firmeza da polpa, evidenciando um processo químico. Sañudo et al. (1997) afirmaram que, com a maturação do fruto, existe a degradação do amido, que é paulatinamente convertido em açúcares solúveis, tornando a firmeza do fruto e da polpa menores, e os frutos, menos resistentes. Castro (1992) afirmou que, na colheita, os valores da força de ruptura da polpa das mangas são maiores que $98 \mathrm{~N}$ e que estes valores decrescem com o tempo, especialmente após o terceiro dia, para cerca de $5 \mathrm{~N}$ na fruta madura. Considerou ainda que mangas maduras devem apresentar valores entre 5 e $10 \mathrm{~N}$ quando maduras e que valores próximos a $2,5 \mathrm{~N}$ indicam mangas excessivamente maduras ou passadas. Durante o amadurecimento do fruto, ocorre a solubilização das protopectinas em pectinas ou ácido péctico, que são polímeros de baixo peso molecular e, conseqüentemente, não conseguem manter a firmeza do fruto ou da polpa (Sigrist, 1992). Neste caso, a firmeza dos frutos orgânicos passou de 113,46 N na colheita para 40,89 N aos 18 DAC; portanto, por este critério, as mangas estavam com boa firmeza 18 DAC, só vindo a ficar impróprias para o consumo aos 32 DAC.

A coloração da polpa dos frutos intensificou-se com o aumento do tempo de armazenamento, assumindo valores máximos aos 32 DAC (Quadro 2). 
No Quadro 3 são apresentadas as médias das avaliações de atributos biológicos de frutos de mangueira cv. Tommy Atkins provenientes de cultivo orgânico, imediatamente após a colheita e após conservação sob refrigeração.

De acordo com o Quadro 3 a ocorrência de colapso interno nos frutos foi nula até 18 DAC. Entretanto manifestando-se em menos de $5 \%$ dos frutos, não diferiu estatisticamente no período de 32 e 46 DAC (Quadro 2). São muito comuns em manga os problemas pós-colheita, sendo o mais grave deles, o colapso interno ou Internal breakdown. O colapso interno se caracteriza pela degradação da polpa, ocasionado sérias perdas econômicas, por ser de difícil detecção, sendo na maioria das vezes detectado apenas pelo consumidor final.

O solo do pomar apresentou 3,3 $\mathrm{cmol}_{\mathrm{c}} \mathrm{dm}^{-3}$ de $\mathrm{Ca}^{+++} \mathrm{Mg}^{++} \mathrm{e}$ o teor de $\mathrm{N}$ nas folhas das mangueiras foi da ordem de 8,83 $\mathrm{mg} \mathrm{dm}-3$, teores alto e baixo, respectivamente. A relação $\mathrm{Ca} / \mathrm{N}=4,9$, o que é uma ótima relação, certamente contribuindo para a excelente sanidade dos frutos no que se refere ao colapso interno nos frutos, aparecendo em alguns poucos frutos na medida em que esses amadureciam. Comparando os teores foliares de nutrientes encontrados no solo e nas árvores dos pomares com os encontrados por Pinto (2002) $\left(\mathrm{Ca}+\mathrm{Mg}_{\text {solo }}=6,05 \mathrm{e} \mathrm{Ca} / \mathrm{N}_{\text {folhas }}=1,77\right) \mathrm{em}$ pomares convencionais, conclui-se que estão baixos os teores de $\mathrm{N}, \mathrm{Mg}, \mathrm{B}, \mathrm{Cu}, \mathrm{Fe}$ e $\mathrm{Mn}$ e altos ou adequados os de $\mathrm{P}, \mathrm{Ca}, \mathrm{K}$ e $\mathrm{Zn}$.

As deteriorações nos frutos causadas por Lasiodiplodia, fungo causador de podridão peduncular, só foram constatadas nos frutos armazenados por mais de 46 DAC com incidência inferior a $5 \%$ dos frutos avaliados (Quadro 3). Quanto aos danos por Colletotrichum, fungo causador da Antracnose, e por Alternaria, causador das manchas de alternaria nos frutos, pouco se manifestaram, senão a partir dos primeiros $18 \mathrm{DAC}$, alcançando valores inferiores a $5 \%$ dos frutos (Quadro 3).

Aos 32 DAC foram constatados $5 \%$ dos frutos apodrecidos, mas não diferia estatisticamente de 46 DAC.

Os danos ou lesões nos frutos devido ao ataque de tripés e ao escurecimento de lenticelas, foram de pouco expressivos, inferiores a $5 \%$ nas deferentes épocas de avaliação. As lesões nos frutos devido ao ataque de tripes foram significativamente maiores na primeira época de avaliação, embora a magnitude do dano tenha sido pequena. O escurecimento de lenticelas aumentou de modo significativo, embora de pequena magnitude $(<5 \%)$ na medida em que aumentou o tempo de armazenamento a frio seguido de 4 dias em sala de amadurecimento. Isso é desejável, visto que um escurecimento expressivo prejudica a aparência dos frutos, dificultando a comercialização.

No Quadro 4 são apresentados os resultados das avaliações dos atributos químicos de frutos de mangueiras no sistema orgânico.

Com o amadurecimento dos frutos, diminuiu a acidez total titulável e aumentaram os teores de sólidos solúveis totais, a relação SST/ATT e o pH, em função da respiração e/ou da conversão de ácidos orgânicos em açúcares (Chitarra \&
Chitarra, 2005). A relação SST/ATT é uma boa expressão para a definição do sabor da polpa da manga. Os teores médios de SST, que eram baixos na colheita $\left(7,89^{\circ}\right.$ Brix), subiram, assumindo valores médios da ordem de 15,08 o Brix 46 DAC, enquanto que com a ATT aconteceu o inverso, variando de 0,84 na colheita e $0,23 \mathrm{mg}$ de ácido cítrico 100 mL-1 de suco, 46 DAC; deste modo, a relação SST/ATT passou de 9,48 na colheita para 66,21 aos 46 DAC.

Em pomares convencionais avaliados por Pinto (2002) os valores médios de SST variaram de $8,30^{\circ}$ Brix, na colheita, a $12,18^{\circ}$ Brix aos 40 DAC, enquanto que os valores médios de ATT variaram de 1,09, na colheita a $0,33 \mathrm{mg}$ de ácido cítrico $100 \mathrm{~mL}^{-1}$ de suco, aos 40 DAC. A relação SST/ATT passou de 7,78 na colheita para 40,80 aos 40 DAC. Conforme Bleinroth (1981) a manga está apta ao consumo quando a relação SST/ATT for superior a 21; deste modo, as mangas estavam aptas para o consumo por volta dos 18 DAC, tempo, mais do que suficiente para se proceder ao transporte do produto até mercados distantes, como o americano e o europeu. $\mathrm{O}$ consumo de ácidos orgânicos no processo respiratório é o principal responsável pela diminuição da acidez e o aumento do pH (Rocha et al., 2001). O pH da polpa passou de 3,72 na colheita para 4,56 aos 46 DAC. Castro (1992) afirma que mangas com pH acima de 3 estão aptas ao consumo, o que aconteceu já na colheita para todos os tratamentos.

\section{Conclusões}

1. Os frutos de mangueiras Tommy Atkins conduzidas sob sistema orgânico, na pós-colheita armazenados sob frio perderam água com o aumento do tempo, não sendo a perda significativa até 14 dias após a colheita (DAC). Os frutos mantiveram boa aparência em todas as épocas de avaliação e os danos mecânicos só se mostraram maiores, embora de pequena magnitude, aos 46 DAC.

2. A coloração da casca dos frutos intensificou-se à medida que aumentou o tempo de armazenamento, até aos 32 DAC.

3. As mangas estavam com boa firmeza 18 DAC, só vindo a ficar impróprias para o consumo aos 32 DAC.

4. Não se constatou a ocorrência de colapso interno nos frutos até 18 DAC, com inexpressiva manifestação após 32 $\mathrm{DAC}$, fato possivelmente associado à alta relação $\mathrm{Ca} / \mathrm{N}$ constatada nas folhas.

5. A sanidade dos frutos foi excelente até 18 DAC, após o que menos de $5 \%$ dos frutos se deterioraram devido a lesões por Lasiodiplodia, Colletotrichum, e, ou, por Alternaria.

6. Aos 32 DAC foram constatados $5 \%$ dos frutos apodrecidos.

7. Os danos ou lesões nos frutos devido ao ataque de tripes e, ou, ao escurecimento de lenticelas, foram pouco expressivos, inferiores a $5 \%$ nas deferentes épocas de avaliação. 


\begin{tabular}{|c|c|c|c|c|c|c|c|}
\hline \multirow{2}{*}{$\begin{array}{l}\text { Tratamentos } \\
\text { (Dias) }\end{array}$} & \multirow{2}{*}{$\begin{array}{c}\text { Colapso } \\
\text { Interno }\end{array}$} & \multicolumn{3}{|c|}{ Deteriorações } & \multirow{2}{*}{$\begin{array}{c}\text { Frutos } \\
\text { Apodrecidos } \\
(\%)\end{array}$} & \multicolumn{2}{|c|}{$\begin{array}{c}\text { Danos causados } \\
\text { por: }\end{array}$} \\
\hline & & Lasiodiplodia & Colletotrichum & Alternaria & & Tripes & Lenticelas \\
\hline 0 & $0,00 b^{y}$ & $0,00 \mathrm{a}$ & $0,00 \mathrm{a}$ & $0,00 a$ & $0,00 \mathrm{a}$ & $0,60 a$ & $0,00 b$ \\
\hline $14+4^{x}$ & $0,00 \mathrm{~b}$ & $0,00 \mathrm{a}$ & $0,05 a$ & $0,20 \mathrm{a}$ & $0,00 \mathrm{a}$ & $0,00 \mathrm{~b}$ & $0,50 a b$ \\
\hline $28+4$ & $0,70 a$ & $0,00 a$ & $0,05 a$ & $0,00 \mathrm{a}$ & $5,00 a$ & $0,00 \mathrm{~b}$ & $0,65 a b$ \\
\hline $42+4$ & $0,50 a b$ & $0,35 a$ & $0,15 a$ & $0,15 a$ & $0,00 \mathrm{a}$ & $0,05 b$ & $0,95 a$ \\
\hline CV (\%) & 111,80 & 278,48 & 164,57 & 179,16 & 447,21 & 142,17 & 100,28 \\
\hline
\end{tabular}

Quatro dias sob a temperatura de $21 \pm 1^{\circ} \mathrm{C}$ e $55-65 \%$ de UR ao final do período de 14,28 ou 42 dias de mazenamento sob refrigeração de $10,5 \pm 1^{\circ} \mathrm{C}$ e $85 \pm 5 \%$ de UR;

Médias seguidas de mesma letra na coluna não diferem entre si pelo teste de Tukey ao nível de $5 \%$ de obabilidade.

Quadro 3.- Valores médios das avaliações de atributos biológicos de frutos de mangueira cv. Tommy Atkins provenientes de cultivo orgânico, Curaçá - BA, 2006-2007, imediatamente após a colheita e após conservação sob refrigeração

\begin{tabular}{ccccc}
\hline \multirow{2}{*}{$\begin{array}{c}\text { Tratamentos } \\
\text { (Dias) }\end{array}$} & Sólidos Solúveis Totais (SST) & $\begin{array}{c}\text { Acidez Total Titulável } \\
\text { (ATT) }\end{array}$ & Relação de SST/ATT & pH \\
\cline { 2 - 5 } & ${ }^{\circ}$ Brix & $\begin{array}{c}\text { mg ác. Cítr. } 100 \mathrm{~mL}^{-1} \mathrm{de} \\
\text { suco }\end{array}$ & & $3,72 \mathrm{~b}$ \\
\hline 0 & $7,89 \mathrm{c}^{y}$ & $0,84 \mathrm{a}$ & $9,48 \mathrm{~b}$ & $3,17 \mathrm{c}$ \\
$14+4^{\mathrm{x}}$ & $14,32 \mathrm{~b}$ & $0,86 \mathrm{a}$ & $17,07 \mathrm{~b}$ & $4,78 \mathrm{a}$ \\
$28+4$ & $15,92 \mathrm{a}$ & $0,25 \mathrm{~b}$ & $63,64 \mathrm{a}$ & $4,56 \mathrm{a}$ \\
$42+4$ & $15,08 \mathrm{ab}$ & $0,23 \mathrm{~b}$ & $66,21 \mathrm{a}$ & 5,13 \\
\hline CV $(\%)$ & 4,90 & 15,79 & 10,84 & \\
\hline \hline
\end{tabular}

${ }^{x}$ Quatro dias sob a temperatura de $21 \pm 1^{\circ} \mathrm{C}$ e $55-65 \%$ de UR ao final do período de 14,28 ou 42 dias de armazenamento sob refrigeração de $10,5 \pm 1^{\circ} \mathrm{C}$ e $85 \pm 5 \%$ de UR;

${ }^{y}$ Médias seguidas de mesma letra na coluna não diferem entre si pelo teste de Tukey ao nível de 5\% de probabilidade.

Quadro 4.- Valores médios das avaliações de atributos químicos de frutos de mangueira cv. Tommy Atkins, provenientes de cultivo orgânico, Curaçá - BA, 2006-2007, imediatamente após a colheita e após conservação sob refrigeração

8. Os valores médios de SST foram mais altos aos 46 DAC do que os constatados em diversos pomares convencionais de alta produtividade da região. A ATT média mostrou valores inferiores aos encontrados em diversos pomares convencionais de alta produtividade da região, o que contribuiu para valores médios mais altos de SST/ATT. O pH da polpa passou de 3,72 na colheita para 4,56 aos 46 DAC, valores mais altos que os encontrados em pomares convencionais da região.

9. As mangas estavam aptas para o consumo por volta dos $18 \mathrm{DAC}$, tempo, mais do que suficiente para se proceder ao transporte do produto até mercados distantes, como o americano e o europeu.

\section{Bibliografia}

Abreu, R. de. (2005) Brasil tem a $2^{\mathrm{a}}$ maior área de agricultura orgânica no mundo. 08/03/2005 Disponível em:

http://www.brasiloeste.com.br/noticia/1424/agriculturaorganica; [27 outubro, 2007].

Barbosa, F. R.; Souza, E. A. de; Silva, C. S. B. da; Carvalho, G. K. L; Gonsalves, M. (2005). Ocorrência de ácaros predadores em dois sistemas de manejo da mangueira: produção integrada e orgânica. In: Simpósio de controle biológico, 9, Recife. Anais. 164-164.
Bleinroth, E. W. (1981). Matéria prima. In: ITAL. Manga: da cultura ao processamento e comercialização. Campinas. cap. 2 , 243-292. (Frutas tropicais, 8)

Britto, W. S. F. Análise da viabilidade financeira da agricultura orgânica versus agricultura convencional: o caso da manga no submédio do vale do São Francisco. Disponível em:http://www.facape.br/agronegocio/07/ waldenir-manga-organica-convencional-sober2004oca498191.pdf. [25 outubro, 2007].

Camargo, A. M. M. P. de; Caser, D. V.; Filho, W. P. de C.; Camargo, F. P. de; Coelho, P. J. (2006). Área cultivada com agricultura orgânica no estado de São Paulo, 2004. Informações Econômicas, SP, 36, 3, mar.

Castro, J. V. (1992). Maturação controlada de frutas. In: Bleinroth, E W.; Sigrist, J. M. M.; Ardito, E. F. G.; Castro, J. V.; Spaagnol, W. A.; Neves Filho, L. C. Tecnologia de pós colheita de frutas tropicais. Campinas: ITAL, 93-102. (Manual Técnico, 9)

Chitarra, M. I. F; Chitarra, A. B. (2005). Pós-colheita de frutos e hortaliças: fisiologia e manuseio. Lavras: Editora da Universidade Federal de Lavras.

Ciociola Junior, A. L.; Martinez, S. S. (2002). Nim: Alternativa no controle de pragas e doenças. Belo Horizonte: EPAMIG. 
Daniel, A. V. (1977). Organic Farming; Quality Control Standards and certification. Proc. National Seminar on Organic Farming and Sustainable Agriculture, Bangalore, India, 9-11 Oct., 145-150.

Galán Saúco, V. (1999). El cultivo del mango. Madrid, Barcelona, México: Gobierno de Canárias (Consejeria de Agricultura, Ganadería, Pesca y Alimentación) e Ediciones Mundi-Prensa.

Gomez - Lim, M. A. (1997). Post harvest physiology. En: Litz, R. E. The mango: botany, production and uses. New York, CAB International, 425 - 445 .

Instituto Adolfo Lutz (1985). Normas analíticas: métodos químicos e físicos para análise de alimentos. 2 ed. São Paulo, SP.

Iyer, C. P. A. (2004). Growing mango under organic system. In: Pinto et al. Eds. Proc. of the Seventh International Mango Symposium, Acta Hort. 645, ISHS. 71- 84.

Nampoothiri, K. V. K. (2001). Organic Farming - Its Relevance to Plantation Crops. Journal of Plantation Crops. 29, 1: 2109.

Neto, M. T. de C. (2005). O uso de farinha de rocha em pomares de manga. Disponivel em: www.cnpmf.embrapa.br/publicacoes/produto em foco/man ga 06.pdf [15 setembro 2007]
Pinto, P. A. da C. (2002). Avaliação do estado nutricional da mangueira Tommy Atkins pelo DRIS e da qualidade pós colheita de frutos no Submédio São Francisco. Viçosa: UFV, 124p. (Tese de doutorado). Disponível em: http://br.geocities.com/pacostapinto/tese.htm; [12 julho 2007]

Rocha, R. H. C.; Menezes, J. B.; Morais, E. A.; Silva, G. G.; Ambrosio, M. M. Q.; Alves, M. Z. (2001). Uso do índice de degradação de amido na determinação da maturidade da manga Tommy Atkins. Revista Brasileira de Fruticultura, Jaboticabal. 23, 2.

Sañudo, R.; Bustillos, R. J. A.; García, L. P. L.; Molina, E. B.; Nuño, S. O.; Algel, D. N. (1997). Manejo postcosecha del mango. México: EMEX.

Schaffer, B.; Whiley, A. W. \& Crane, J. H. (1994). Mango. Handbook of Environmental and Physiology of fruit crops. Vol II: subtropical and tropical crops. Press. Boca Raton, 165-197. 